\title{
EL DISCURSO RESOCIALIZADOR: HACIA UNA NUEVA PROPUESTA PARA EL SISTEMA PENITENCIARIO
}

\author{
Mario A. Sáenz Rojas*
}

\author{
... enseñarle a vivir en libertad a alguien \\ privado de libertad es como enseñarle \\ a jugar fútbol a alguien adentro de un ascensor... \\ (Zaffaroni)
}

RESUMEN

El presente artículo analiza la finalidad de la pena privativa de libertad en función del mandato legal inspirado en el discurso resocializador y en el marco de una política criminal respetuosa de los derechos humanos. Así, se realiza una crítica fundamentada a las concepciones retributivas y del derecho penal simbólico. Se reflexiona sobre el concepto de política criminal en un estado social y democrático de derecho, se define el concepto de resocialización, así como sus críticas en relación con el diagnóstico criminológico y el tratamiento penitenciario, finalizando con una discusión sobre dicho propósito, contraponiéndolo con resoluciones constitucionales e instrumentos jurídicos internacionales.

PALABRAS CLAVE: COSTA RICA * CRIMINOLOGÍA * PENOLOGÍA * SISTEMA PENITENCIARIO $*$ DERECHOS HUMANOS $*$ POLÍTICA CRIMINAL

ABSTRACT

This article analyzes the finality of the privation penalty of freedom in function of the legal mandate inspired on the resocializator speech and on the context of a criminal respectful policy of the human rights. Likewise, a criticism is made based upon the retributive conceptions and the symbolical penal right. There is a reflection about the criminal policy concept within a social and democratic social right, the concept of resocialization is defined, as well as its judgments in relation with the criminological diagnosis and the penitentiary treatment, concluding with a discussion related to such purpose, comparing with constitutional resolutions and international juridical instruments.

KEY WORDS: COSTA RICA * CRIMINOLOGY * PENOLOGY * PRISON SYSTEM * HUMAN RIGHTS * CRIMINAL POLICY 


\section{INTRODUCCIÓN}

El reciente acontecer nacional ha conllevado la generación de una serie de sentimientos ciudadanos vinculados con mayores medidas draconianas como formas de control de la criminalidad ${ }^{1}$, situación que además, ha generado modificaciones legislativas antojadizas ${ }^{2}$. En este sentido, si bien algunos autores han considerado que Costa Rica ha carecido de una política crimi$\mathrm{nal}^{3}$, lo cierto es que en la práctica se ha caracterizado por un conjunto de medidas represivas, a

Cfr. Carranza Lucero, Elías. Criminalidad: ¿Prevención o promoción? San José: Editorial de la Universidad Estatal a Distancia./ Fournier Facio, Marco Vinicio. "La violencia en Costa Rica: un problema estructural”. Ciencias Penales, mayo-1999, 16, 61-63./ Sáenz Rojas, Mario Alberto. "La inseguridad ciudadana: los aportes de Ignacio MartínBaró y la criminología crítica”. Revista de Ciencias Sociales de la Universidad de Costa Rica, setiembre-1995, 69, 29-41. "El papel de los medios de comunicación en la construcción social del fenómeno de la criminalidad", Cuadernos de Estudio del Ministerio Público de Costa Rica, 2004, 8, 49-57.

En este sentido se han producido varias reformas al Código Penal, tales como: 1. la del artículo 55, por medio de la cual sólo se puede disfrutar del descuento de la pena por trabajo hasta la segunda mitad de la condena impuesta, lo que se traduce innegablemente en más tiempo efectivo de prisión (Ley 7398 del 3 de mayo de 1994); 2. la del artículo 51, que incrementa el límite máximo de las penas de 25 a 50 años de prisión (Ley 7389 del 22 de abril de 1994); 3. el incremento de los montos de las penas privativas de libertad para una serie de delitos, por ejemplo, los delitos sexuales (artículos 156, 157 y 158 mediante Ley 7398); los homicidios dolosos (artículos 111 y 112 por medio de Ley 7398) y robo de autos, entre otros, $v$ gr., en el año 1994 el homicidio calificado pasó de tener una pena que oscilaba entre 15 y 25 años de prisión a otra de 20 a 35 años); o bien, 4. la del capítulo de contravenciones, por medio de la cual se impone pena de prisión a ciertas acciones que se castigaban con días multa.

Al respecto: "Costa Rica nunca ha tenido una política criminal debidamente estructurada. En su lugar, la política que en esta materia ha existido ha sido oportunista e ineficaz..." (Castillo González, Francisco, citado por Universidad Estatal a Distancia. Programa de Maestría en Criminología. San José. UNED, 2001: 3). pesar de establecer como fin último de la privación de libertad la resocialización.

Es así como, no hay una política criminal única, sino que esta se manifiesta por medio de distintas tendencias.

Quiénes hoy hablan de la política criminal como uno de los temas más progresivos de la dogmática, como la vanguardia del saber jurídico-penal, olvidan, no obstante, que también Hitler, Mussolini y Stalin tenían sus «políticas criminales», las cuales, si de control se trata, fueron de las más «efectivas» de la historia de nuestro siglo ${ }^{4}$.

De esta manera, se hace necesario analizar el fondo ideológico que sustenta este discurso resocializador, con el objetivo de promover la discusión a este respecto $y$, en consecuencia, redimensionar tal concepto en función del máximo respeto a los derechos humanos de las personas privadas de libertad $y$ de rechazo a la retribución por el daño provocado.

Para tales efectos, este trabajo se ha organizado en tres partes. La primera desarrolla el tema de la política criminal, definiendo este concepto y reseñando los elementos constitutivos de la propuesta de Roxin en el marco de la doctrina alemana. Una segunda parte se dedica al acápite de la resocialización, inicia con la conceptualización del término y presta suma atención a las críticas que se le han efectuado, para concluir con las definiciones y el cuestionamiento del diagnóstico criminológico y el tratamiento penitenciario. Como última parte se plantea la discusión, en la cual se confrontan las ordenanzas legales con los instrumentos jurídicos internacionales en materia de derechos humanos y diversas resoluciones de la Sala Constitucional de la Corte Suprema de Justicia.

Salas, Minor E. "Mitomanías de la «política criminal» moderna". Cuadernos de Estudio del Ministerio Público de Costa Rica, 2004. 8: 42. 


\section{EL CONCEPTO DE POLÍTICA CRIMINAL}

\section{II.a. DEFINICIÓN}

Tal como señala Zúñiga ${ }^{5}$, la posición que se asume en cuanto a la concepción de la política criminal depende en buena medida de la ubicación paradigmática del autor respectivo. En este sentido, se han planteado tres corrientes ideológicas subyacentes con carácter fundamental: la corriente liberal, la corriente igualitaria y la corriente autoritaria ${ }^{6}$, pues "toda política es impulsada por una ideología"

Desde este punto de vista, también se sostiene que en el marco de un Estado social y democrático de derecho, el fin general de la política criminal debe ser la protección y la defensa de los derechos fundamentales de las personas.

Sepúlveda refiere que la política criminal hace alusión a “... los medios empleados por el Estado para prevenir $y / 0$ reprimir la criminalidad"8.

Mientras tanto, para efectos del presente trabajo se comparte la definición de DelmasMarty, la cual reza: "Conjunto de modelos con los que el cuerpo social organiza las respuestas al fenómeno criminal"9. A criterio de esta autora, tal definición permite una concepción más amplia, pues se pasa:

a) de los métodos represivos a otros, especialmente reparadores o mediadores,

b) de la reacción del Estado a la respuesta del cuerpo social,

5 Cfr. Zúñiga Rodríguez, Laura. Política criminal. (Capítulos 1 y 4 seleccionados en la Antología del curso de Política Criminal 2003. Universidad Estatal a Distancia).

6 Cfr. Delmas-Marty, Mireille. Modelos actuales de política criminal. Madrid: Centro de Publicaciones, Secretaría General Técnica. Ministerio de Justicia. 1986.

$7 \quad$ Ibid, p. 26 .

8 Sepúlveda, Juan Guillermo. "Política criminal". En: Asociación Colombiana de Criminología (editora). Lecciones de Criminología. Bogotá. Editorial Temis. 1988. p. 87.

Delmas-Marty, op. cit., p. 19. c) de una respuesta de reacción a una respuesta preventiva, $y$

d) del crimen al fenómeno criminal.

De acuerdo con Muñoz-Conde, "es típico de la actual ciencia del derecho penal olvidar o marginar los problemas políticos, económicos $y$ sociales en beneficio de los puramente técnico-jurídicos o dogmáticos"10. Partiendo de este nivel de análisis es que Velásquez señala que una verdadera política criminal no puede estar desligada de la política social del Estado; de esta manera, la política criminal tiene como finalidad denunciar e influir en el cambio de las relaciones de dependencia que se producen en la estructura social y que favorecen la ocurrencia de actos delictivos ${ }^{11}$.

\section{II.b. LA PROPUESTA DE LA ESCUELA ALEMANA}

Enmarcado en una postura eminentemente minimalista-garantista, Roxin esboza diez tesis ${ }^{12}$ para una Política Criminal moderna, a saber:

1) El derecho penal debe limitarse a la protección de bienes jurídicos ${ }^{13}$.

2) El derecho penal sólo debe utilizarse en tanto última ratio, hay que postular la descriminalización sin atentar contra un orden social pacífico.

3) La retribución no constituye el fin de la pena, esta sólo se encuentra en necesidades de prevención general y especial.

10 Muñoz Conde citado por Velásquez Lyons, Luis Felipe. "Política social y Política criminal". En: Asociación Colombiana de Criminología (editora), op. cit., p. 109.

11 Cfr. Velásquez Lyons, op. cit.

12 Cfr. Roxin, Claus. "El desarrollo de la política criminal desde el Proyecto Alternativo". En: Mir Puig, Santiago (editor). Política criminal y reforma del Derecho Penal. Bogotá. Editorial Temis. 1982, pp. $5-27$.

13 Cfr. Voto de la Sala Constitucional nro. 525-93 del 3 de febrero de 1993. Al respecto, la Sala ha señalado que los bienes jurídicos no se equiparan con valores morales o ético-sociales. 
4) Es necesario conservar el principio de culpabilidad con el propósito de limitar el poder estatal.

5) La privación de libertad debe imponerse $y$ ejecutarse como pena unitaria.

6) Hay que hacer desaparecer la pena de privación de libertad de hasta seis meses ${ }^{14}$.

7) La pena privativa de libertad de hasta dos años hay que sustituirla por pena pecuniaria.

8) La pena pecuniaria puede ser sustituida por trabajo socialmente útil o servicio a la comunidad.

9) La pena privativa de libertad debe ser suspendida a prueba si es inadecuada y si hay una prognosis fiable.

10)La fase de ejecución debe estar organizada bajo una perspectiva socializadora.

Paralelamente, de acuerdo con Bustos Ramírez, el planteamiento dialéctico de Roxin consiste en ubicar las diferentes finalidades de la pena (retribución, prevención general y prevención especial), ya sea en el momento de creación, en el de aplicación o en el de ejecución de la norma penal ${ }^{15}$.

En el primer momento que coincide con las conminaciones penales, la finalidad es de prevención general; en el segundo, en el cual se impone la pena previa medición de la pena que corresponde a la culpabilidad, la finalidad tiene un doble sentido retributivo/preventivo general; por último, en el tercer momento, la finalidad de la pena es de prevención especial (resocialización del delincuente).

En este enfoque dialéctico la retribución aparece limitada por los momentos de prevención general y especial. En el momento de la síntesis, Roxin opta por la prevención especial, ya que beneficia a quien delinque $y$ a la sociedad, condicionada por la función limitadora del principio de culpabilidad.

A este respecto, por ejemplo, el Código Penal español de 1995 ha eliminado las penas inferiores a un año de prisión por considerar que este monto es insuficiente para alcanzar una meta resocializadora.

Cfr. Arroyo Gutiérrez, José Manuel. El sistema penal ante el dilema de sus alternativas. San José. Editorial Gráfica Brenes. 1995.
Por otra parte, Jacobs plantea que, particularmente el derecho penal está conformado por un conjunto de normas que conllevan expectativas de comportamientos en torno a la comunidad jurídica, de lo cual se deduce el papel estabilizador que desempeña el derecho penal cuando las normas jurídicas son violentadas, donde la pena tiene como finalidad mantener dichas normas como orientación y modelo de los comportamientos sociales ${ }^{16}$.

Asimismo, para Hassemer la pena tiene una función estabilizadora, en tanto asegura el respeto a la norma en la conciencia jurídica del cuerpo social, limitada por el principio de culpabilidad (en cuanto retribución por el daño causado) $y$ sin renunciar al objetivo resocializador en la medida de lo posible ${ }^{17}$.

\section{EL PROGRAMA RESOCIALIZADOR}

\section{III.a. EL CONCEPTO DE RESOCIALIZACIÓN}

La prevención especial positiva, entendida como reeducación y reinserción social de los condenados, implica la resocialización del delincuente; o sea, una función correctora y de mejora del delincuente ${ }^{18}$. Esto se puede traducir, normativamente, así: “... llevar en el futuro en responsabilidad social una vida sin delitos"19.

Más precisamente, desde el punto de vista penológico se puede afirmar que “... la resocialización debe consistir en hacer aceptar al delincuente las normas básicas y generalmente vinculantes que rigen una sociedad" 20 .

Desde la perspectiva de los y las profesionales en psicología, en tanto operadores del sistema penitenciario, muy acertadamente Víquez

Cfr. Ibid.

Cfr. Ibid.

Cfr. Muñoz Conde, Francisco. "La resocialización: análisis y crítica de un mito". En: Mir Puig, Santiago (editor), op. cit. Bogotá. Editorial Temis. 1982, pp. 131-154.

Ibid, p. 132, Así lo establece la Ley Penitenciaria alemana del 16 de marzo de 1976. 
ha señalado que se trata del ejercicio de la violencia técnica, por cuanto se trata de convencer al desviado de su propia desviación en el marco de una relación totalmente asimétrica ${ }^{21}$.

Este modelo y su concepción se fundamentan en el paradigma etiológico de raigambre positivista, discurso que se recubre con un ropaje cientificista, recurriendo a los conocimientos de ciertas disciplinas (p. ej. sociología, psicología, antropología, medicina, entre otras). Este paradigma se centra en el autor del hecho punible con el propósito de establecer una clara distinción entre quienes se adaptan y quienes violan la norma jurídica; de esta manera, se trata de explicar las diferencias entre ambos grupos por supuestas alteraciones de carácter genético, antropológico o psiquiátrico, según corresponda.

Así, por ejemplo, Marchiori relaciona al estafador con personalidades histéricas, “... el estafador (impostor) siempre busca una identidad para justificar su narcisista concepción de sí mismo, pero que a su vez niega su propia identidad. Necesita satisfacer fantasías de grandeza actuando y tratando de demostrar su concordancia y semejanza con el ideal del yo" 22 .

En el seno de este paradigma surgió lo que se denominó "criminología clínica" 23 , concebida como el estudio de la persona humana para buscar en ella la causa de sus acciones, particularmente, aquellas excepcionales como las delictivas. Y fue precisamente esta postura la que sirvió para impulsar el sistema penitenciario progresivo, ideología y praxis que dominaron la ejecución de la pena en Costa Rica durante las décadas de 1970 y 1980.

21 Cfr. Víquez Jiménez, Mario Alberto. "El rol del psicólogo criminológico en la institución carcelaria: una autocrítica". En: Revista Costarricense de Psicología, junio/diciembre-1988, 12-13, pp. 47-55.

Cfr. Marchiori, Hilda. La personalidad del delincuente. Tercera edición. México D. F. Editorial Porrúa, 1990, p. 79.

Cfr. Di Tulio, Benigno. Principios de Criminología Clínica y Psiquiatría Forense. Madrid: Aguilar editores, 1966.

\section{III.b. CRÍTICAS AL MODELO RESOCIALIZADOR}

De acuerdo con una postura propia de la criminología crítica, Baratta señala que no es el sujeto delincuente, sino la sociedad que lo produce la que debería ser objeto de resocialización ${ }^{24}$. En este sentido y en relación con el epígrafe, se ha planteado que la privación de libertad es un obstáculo para un tratamiento resocializador y, además, posee efectos deteriorantes sobre el penado.

En la cárcel el sujeto no aprende a vivir en sociedad, sino a perseguir y aún perfeccionar su carrera criminal a través del contacto y las relaciones con otros delincuentes. Todavía peor es que el condenado adopte una actitud pasiva o conformista, e incluso de cooperación con los funcionarios, pues esto último se debe las más de las veces a la mayor posibilidad de conseguir por esa vía mejor trato, comodidades de tipo material o incluso la concesión de determinados beneficios, como el traslado a un establecimiento penitenciario abierto o la concesión de la libertad condicional ${ }^{25}$.

Para Beloff ${ }^{26}$, las principales críticas a la resocialización como modelo de prevención del delito, pueden sintetizarse de la siguiente manera:

1) Los presupuestos de su eficacia no coinciden con los de la concepción que vincula la pena con la culpabilidad ${ }^{27}$.

2) En ciertos casos podría caerse en una flagrante violación del principio de proporcionalidad, al proponerse penas perpetuas o indeterminadas.

24 Cfr. Muñoz Conde, op. cit.

$25 \quad$ Ibid, p. 147.

26 Cfr. Beloff, Mary. "Teorías de la pena: la justificación imposible". (Capítulo seleccionado en la Antología del curso Teorías y Enfoques sobre la Sanción Penal 2003. Universidad Estatal a Distancia).

27 En el caso costarricense, esta crítica es aún más evidente en el caso del procedimiento abreviado y el reproche jurídico. 
3) Se debería sustituir la pena por medidas de carácter terapéutico.

4) El único límite de la ejecución de la pena sería el éxito del tratamiento, lo cual podría dar pie a imprecisiones $y$ arbitrariedades.

5) La privación de libertad acentúa o consolida el deterioro del condenado (efecto iatrogénico de la prisionalización).

Además, Muñoz Conde considera que la resocialización es tendenciosa, puesto que implica adaptarse a las expectativas de la clase media; de ahí que según Schellkoss, generalmente se acepte que los delincuentes adaptados a la forma de vida burguesa no requieren resocialización ${ }^{28}$, situación que comúnmente agudiza la selectividad y diferenciación que establece el sistema de justicia penal. Este autor señala también como parte de sus críticas, la ineficacia del tratamiento, la afectación de los derechos fundamentales de los condenados ante la obligatoriedad del tratamiento, $y$ la carencia de medios adecuados $y$ personal debidamente capacitado para llevar a cabo ese tratamiento ${ }^{29}$.

Asimismo, cabe destacar aquellas críticas producto de la homologación entre tratamiento penitenciario y régimen disciplinario ${ }^{30}$.

Por su parte, García-Pablos de Molina ${ }^{31}$ adiciona las siguientes críticas:

1) Implica un proceso de aprendizaje de valores que el sujeto debe "interiorizar" y, por lo tanto, tiene un fundamento moralizante $y$ valorativo.

2) El fundamento pedagógico o método de aprendizaje es bastante objetable, pues para

28 Cfr. Muñoz Conde, op. cit.

29 Cfr. Ibid.

30 Cfr. Mosconi, Giusseppe. "Paradojas y antinomias del concepto de tratamiento". (Capítulo seleccionado en la Antología del curso Teorías y enfoques sobre la sanción penal 2003. Universidad Estatal a Distancia).

31 Cfr. García-Pablos de Molina, Antonio. "La supuesta función resocializadora del derecho Penal”. (Capítulo seleccionado en la Antología del curso Teorías y enfoques sobre la sanción penal 2003. Universidad Estatal a Distancia). enseñar la interiorización de esos valores utiliza el encierro. En otras palabras, para enseñar cómo vivir en libertad se le quita al ser humano esa libertad.

3) La resocialización implica, necesariamente, un tratamiento, lo cual es criticado por las posiciones liberales, ya que una persona no puede ser "adecuable" a la visión de mundo de otras ${ }^{32}$.

4) Si la sociedad es la que produce la delincuencia, resulta contraproducente y contradictorio exigirle al individuo que se resocialice; esto hace del programa resocializador algo "ideológico", a saber, tendencioso y manipulador hacia una determinada concepción de mundo.

De esta manera, resulta claro que el derecho penal y la ejecución de medidas privativas de libertad no han cumplido la función de evitación del delito, aunado a que han producido un significativo nivel de violencia institucionalizada, ya que en tanto institución total

... la cárcel no sirve para la rehabilitación del encarcelado, así como tampoco el manicomio sirve para la rehabilitación del enfermo mental. Ambos responden a una exigencia (...) del sistema social, que tiene como fin último la marginación de quien rompe con el juego social. La marginación del que no acepta la problemática de la violencia institucionalizada que gobierna a nuestra sociedad ${ }^{33}$.

32 Las denominadas valoraciones técnicas, establecidas en el Reglamento Orgánico y Operativo de la Dirección General de Adaptación Social (artículos 68, 69 y 70 del Decreto Ejecutivo 22198-J, publicado en el Diario Oficial La Gaceta 104 del $1^{\circ}$ de junio de 1993 y sus reformas) son una muestra de esta crítica, puesto que se evalúa la medida en que una persona privada de libertad se adecúa o no a lo que otras personas han considerado como conveniente para la primera.

33 Basaglia, Franco. "La institucionalización psiquiátrica de la violencia”. En: Suárez, Armando (compilador). Razón, locura y sociedad. Quinta edición. México D. F. Siglo XXI editores. 1982, pp. 16-17. 


\section{III.c. LOS CONCEPTOS DE DIAGNÓSTICO Y TRATAMIENTO}

Para el programa resocializador el "diagnóstico" es la base organizadora sobre la que se cimentan las pautas para la vida en la cárcel, pautas que, desde la perspectiva institucional, tienen la finalidad de favorecer la construcción de un proyecto de vida en libertad ${ }^{34}$.

Por otra parte, frente a la crisis de gobernabilidad y legitimación carcelaria se ha desarrollado la idea de una pena más humana, orientada al mismo tiempo a la maduración de la personalidad y a la reinserción social del detenido. Esto remite necesariamente al concepto de tratamiento, el cual ha sido criticado duramente por su asociación con el respeto al régimen disciplinario de la institución, lo cual tendría un carácter correccionalista y moralizante $e^{35}$.

No cabe duda que estos conceptos son producto del saber psiquiátrico, discurso que al igual que el derecho penal está dirigido al control social de la desviación.

En el plano penitenciario costarricense el tratamiento ha cobrado vigencia en dos modelos en apariencia distintos. En el modelo progresivo se propone un etapismo a lo largo del cual, y por efecto de la resocialización, se prepara al interno para su vida en libertad ${ }^{36}$. Esto se operativizaba, en primer lugar, mediante el diagnóstico criminológico que permitía ubicarlo en una etapa determinada dentro del sistema y, en segundo lugar, recurriendo a diversas actividades tales como: trabajo, educación y psicoterapia, entre otras.

Con la puesta en vigencia del Plan de Desarrollo Institucional del Ministerio de Justicia, se pretende dejar de lado la visión positivista $y$ se plantea como acción institucional la atención técnica en áreas específicas en las cuales el privado de libertad presenta algún tipo de déficit. Estas áreas hacen alusión al trabajo, a la educación, a la convivencia intracarcelaria; o bien a

34 Cfr. Víquez Jiménez, Mario Alberto. "El diagnóstico y la síntesis criminológica”. Alajuela. Centro Nacional de Diagnóstico CriminológicoPenitenciario, s. $f$.

Cfr. Mosconi, op. cit. problemáticas específicas como la drogadicción $y$ la violencia sexual, para las cuales se prescriben grupos de carácter terapéutico.

En este sentido, "podría afirmarse que el Plan de Desarrollo Institucional no ha pasado a ser más que un cambio de fachada porque en la institución subsiste la ideología represiva base del Sistema Progresivo..."371. Esta crítica, emanada de un juez de ejecución de la pena reviste gran importancia, puesto que evidencia su experiencia de garantizar los derechos fundamentales de quienes se encuentran privados de su libertad.

Empero, quizás lo más grave es que, tanto en uno como en otro modelo, la institución penitenciaria parte implícitamente de la obligatoriedad del tratamiento, debido a que, si el privado de libertad no se somete a él, esto repercutiría negativamente en su evaluación o valoración técnica.

Ahora bien, la imposición del tratamiento en un Estado de derecho resulta inadmisible, ya que no se pueden imponer determinadas costumbres o modificaciones de la personalidad a un individuo. Lo anterior encuentra sentido en que tal imposición constituiría una violación a los principios de autonomía y dignidad; aunado a que el respeto a la dignidad humana durante la ejecución de la pena privativa de libertad está asegurada por disposiciones constitucionales ${ }^{38}$.

\section{DISCUSIÓN}

En el ámbito nacional cabe iniciar señalando que desde varias décadas atrás, el artículo 51 del Código Penal establece una finalidad resocializadora de la pena privativa de libertad.

Así dice su primer párrafo:

La pena de prisión y las medidas de seguridad se cumplirán en los lugares y en la forma que una ley especial lo determine,

37 Murillo Rodríguez, Roy. Ejecución de la pena. San José: CONAMAJ, 2002, p. 79.

38 Cfr. Votos de la Sala Constitucional 6829-93 del 24 de diciembre de 1993 y 672-97 del 31 de enero de 1997. 
de manera que ejerzan sobre el condenado una acción rehabilitadora ${ }^{39}$.

Por otra parte, la Ley de Justicia Penal Juvenil (Ley 7576) hace alusión a la "formación integral" y la "reinserción familiar y social" como sus principios rectores (artículos 7, 29, 44, 123, 133, 136 inciso e, y 138 inciso e 3$)^{40}$.

Asimismo, la Sala Constitucional ha establecido mediante dos votos ${ }^{41}$ que junto al respeto de la dignidad humana durante la ejecución de las penas privativas de libertad se impone la ordenanza de lo estipulado en el recién mencionado artículo 51 del Código Penal. Uno de dichos votos establece: Junto al principio de humanidad, que debe privar en la ejecución penal, se acentúa en nuestro medio la aspiración rehabilitadora (artículo 51 del Código Penal)... ${ }^{42}$.

A pesar de lo anterior, en ningún otro lugar se ofrece mayor detalle sobre el fin resocializador de la pena, quizás porque el mismo artículo 51 del Código Penal hace alusión a una ley especial (ley de ejecución) que aún no se ha aprobado.

No cabe duda que el hecho de que se mantenga este propósito de resocialización permite darle un sentido a la pena y evitar que la misma sea puramente retributiva, por lo menos en el plano discursivo. No obstante, la misma Sala Constitucional ha considerado lo siguiente:

... La pena es la justa retribución del mal ocasionado por el ilícito penal, proporcional a la culpabilidad del imputable. Sin negar la posible finalidad resocializadora $y$ en alguna medida preventiva de la pena, su esencia radica en la retribución, retribución que no se traduce en reproche 0 venganza; sus fines son más amplios $y$ elevados: mantener el orden y el equilibrio, fundamento de la vida moral $y$

39 Costa Rica. Leyes, decretos, etc. Código Penal. San José. Editorial Porvenir. Decimosegunda edición, 1998, p. 14. La cursiva no es del original.

40 Cfr. Costa Rica. Leyes, decretos, etc. Ley de Justicia Penal Juvenil. San José. Imprenta Nacional, 1996.

41 Se refiere a los votos de la Sala Constitucional 6829-93 del 24 de diciembre de 1993 y al 672-97 del 31 de enero de 1997 (supra). social, para protegerlos y restaurarlos en caso de quebranto...43.

Lo expuesto en este fallo constitucional pareciera sumamente grave, pues responde a lo que García-Pablos de Molina ${ }^{44}$ denomina "neorretribucionismo", en nombre de la eficacia y el defensismo del derecho penal $y$, de alguna manera, resulta en una tentativa de legitimación del sistema penal.

De esta manera, por el contrario, de acuerdo con Roxin, la finalidad retributiva está en el momento de la creación de la norma penal; mientras que el objetivo resocializador es propio de la fase de ejecución de la sanción. Ahora bien, la resocialización en esta fase debe estar limitada por los principios de culpabilidad y proporcionalidad, $y$ sobre todo, mediatizada por el supremo respeto de los derechos fundamentales garantizados en la Constitución Política propia de un Estado social y democrático de derecho. Para concretar esta propuesta desde una óptica minimalista-garantista es menester la redacción y aprobación de una Ley de Ejecución Penal o un Código Penitenciario que limite la acción y el poder estatal encarnado en la administración penitenciaria, por medio de un estricto control jurisdiccional. De esta manera, debe insistirse en el fin resocializador durante la fase de ejecución pero desde una nueva perspectiva, ya no como una forma de legitimar el sistema penal, ni como un planteamiento de "curación" de la "patología delictiva", sino como la negación del retribucionismo y el aseguramiento del respeto a la dignidad humana y los derechos consagrados en el ordenamiento jurídico nacional y los instrumentos internacionales de derechos humanos ${ }^{45}$.

Voto de la Sala Constitucional 2586-93 del 8 de junio de 1993. La cursiva no es del original.

44 Cfr. García-Pablos de Molina, op. cit.

45 Respecto a la violación de derechos fundamentales durante la fase de ejecución de la pena en Costa Rica, los lectores interesados pueden referirse a: Chan Mora, Gustavo y García Aguilar, Rosaura. Los derechos fundamentales tras los muros de la prisión. San José. CONAMAJ. 2003./ Issa El Khoury, Henry y Arias, María Gerarda. Derechos Humanos en el sistema penal. San José: Editorial de la Universidad Estatal a Distancia. 1998./ Murillo Rodríguez, Roy, op. cit. 
En este sentido, las Reglas Mínimas de Naciones Unidas para el Tratamiento de los Reclusos han establecido:

58: El fin y la justificación de las penas $y$ medidas privativas de libertad son, en definitiva, proteger a la sociedad contra el crimen. Solo se alcanzará este fin si se aprovecha el periodo de privación de libertad para lograr, en lo posible, que el delincuente una vez liberado no solamente quiera respetar la ley y satisfacer sus necesidades, sino también que sea capaz de hacerlo ${ }^{46}$.

Si bien lo anterior podría interpretarse ligeramente como un principio retribucionista, lo cierto es que en el numeral siguiente, las mismas reglas mínimas circunscriben la protección de la sociedad a la resocialización durante el periodo de reclusión, en concordancia con las últimas líneas de la propia regla 58 :

59: Para lograr este propósito, el régimen penitenciario debe emplear todos los medios curativos, educativos, morales, espirituales $y$ de otra naturaleza, $y$ todas las formas de asistencia de que puede disponer, tratando de aplicarlos conforme a las necesidades del tratamiento individual de los delincuentes ${ }^{47}$.

Vale en este punto recordar que la Sala Constitucional le ha dado a las reglas mínimas supracitadas rango de derechos constitucionalmente reconocidos para las personas privadas de libertad:

En las Reglas Mínimas para el Tratamiento de los Reclusos, adoptadas por la Organización de las Naciones Unidas, se establecen lineamientos que deben ser aplicado (sic) en todos los Centros de Atención Institucional del país, por lo que debe entenderse que cada una de estas reglas que regulan sobre las condiciones

46 Reforma Penal Internacional. Manual de buena práctica penitenciaria. San José: Editorial Guayacán. Segunda edición. 2002. p. 187. mínimas con las que debe contar un recluso, son sus derechos, constitucionalmente reconocidos ${ }^{48}$.

El mismo tribunal constitucional ha señalado en concordancia con lo anterior:

... son aplicables a nuestro país a la luz del artículo 48 de la Constitución Política que ha elevado todos los instrumentos internacionales sobre derechos humanos, a rango constitucional, los que deberán ser incorporados en la interpretación de la Constitución sobre todo en materia de derechos humanos ${ }^{49}$.

Por otra parte, el Pacto Internacional de Derechos Civiles y Políticos reza:

ART. 10.1.: "Toda persona privada de libertad será tratada humanamente $y$ con el respeto debido a la dignidad inherente al ser humano"50.

Aún más,

... tratándose de instrumentos internacionales de Derechos Humanos vigentes en el país, no se aplica lo dispuesto en el artículo 7 de la Constitución Política, ya que el 48 Constitucional tiene norma especial para los que se refieren a derechos humanos, otorgándoles una fuerza normativa del propio nivel constitucional. Al punto de que, como lo ha reconocido la jurisprudencia de esta Sala, los instrumentos de Derechos Humanos vigentes en Costa Rica, tienen no solamente un valor similar al de la Constitución Política, sino que en la medida que otorguen mayores derechos o garantías a las personas, priman por sobre la Constitución... ${ }^{51}$.

48 Voto de la Sala Constitucional nro. 3502-97 del 20 de junio de 1997.

49 Voto de la Sala Constitucional nro. 709-91 del 10 de abril de 1991.

50 Reforma Penal Internacional, op. cit., p. 169.

51 Voto de la Sala Constitucional nro. 2313-95 del 9 de mayo de 1995. 
De esta manera, mientras que por una parte la Sala Constitucional acepta un fin retributivo para la pena privativa de libertad, por el otro, reconoce con rango constitucional todos aquellos instrumentos jurídicos internacionales en materia de derechos humanos, siendo que, las propias reglas mínimas elaboradas por Naciones Unidas establecen un propósito resocializador ${ }^{52}$; en otras palabras, por un lado la Sala se apega a ciertas posturas conservadoras amparadas en el derecho penal simbólico $y$, por el otro, enarbola el estandarte de los derechos fundamentales, llevándolos inclusive al plano de la ejecución penal, a pesar de las serias deficiencias que se pueden encontrar en el mismo. Lo anterior podría asociarse, con la presión que ejercen los medios de difusión de masas y la opinión pública sobre las autoridades judiciales y penitenciarias, con fundamento en la denominada "inseguridad ciudadana" y el clamor popular por medidas represivas, tales como la tortura, la elevación de las penas de prisión o la instauración de la pena de muerte, ante la presencia cada vez mayor de actitudes autoritarias en la población nacional ${ }^{53}$.

No obstante la contradicción recién señalada, se debe tener cuidado en no caer en un falso debate, que coloque el enfrentamiento en el desierto estéril de discursos de lobo con piel de oveja, puesto que en torno al rol profesional del criminólogo, precisamente Pérez Pinzón ${ }^{54}$ indica que este debe ser vigilante de la libertad y la igualdad, independientemente del paradigma en que se encuentre ubicado $y$, sobre todo, no debe ser defensor del statu quo pero sí de los derechos humanos. Lo anterior remite a la necesidad de asumir como única finalidad de la ejecución penal la resocialización, entendida como negación de la retribución por el daño causado y como máximo respeto de los derechos humanos de las personas privadas de libertad sujetas a la ejecución de una sentencia condenatoria.

Recuérdese a este respecto las reglas nro. 58 y 59 citadas supra.

53 Cfr. Fournier Facio, Marco Vinicio, op. cit./ Sáenz Rojas, Mario Alberto, op. cit. 2004.

54 Cfr. Pérez Pinzón, Álvaro; citado por Salgado González, Álvaro. "Modelos o paradigmas de la
Ahora bien, aceptar la resocialización como principio rector de la ejecución penal no significa en absoluto legitimar la pena; por el contrario, significa humanizar la acción represiva del Estado, puesto que además de entenderse como negación de la retribución y defensa de los derechos humanos, debe también colegirse que es negación del principio preventivo, ya sea general o especial, debido a que la prevención del delito no radica jamás en la imposición de penas, sino en la política social de un Estado ${ }^{55}$.

\section{REFERENCIAS}

Arroyo, J. M. El sistema penal ante el dilema de sus alternativas. San José. Gráfica Brenes. 1995.

Basaglia, F. (1974). La institucionalización psiquiátrica de la violencia. En: A. Suárez (Ed.) Razón, locura y sociedad. México D. F. Siglo xxi. 1982.

Carranza, E. Criminalidad: ¿Prevención o promoción? San José. Universidad Estatal a Distancia. 1994.

Chan, G. y García, R. Los derechos fundamentales tras los muros de la prisión. San José. Comisión Nacional para el Mejoramiento de la Administración de Justicia. 2003.

Costa Rica. Leyes, decretos, etc. Ley de Justicia Penal Juvenil. San José. Imprenta Nacional. 1996.

Costa Rica. Leyes, decretos, etc. Código Penal. $12^{a}$ ed. San José. Porvenir.1998.

criminología actual”. En: Asociación Colombiana de Criminología (editora), op. cit., pp. 15-18.

Cfr. Sáenz Rojas, Mario Alberto. "La prevención del delito: un cambio paradigmático". Cuadernos de Estudio del Ministerio Público de Costa Rica, 2005. 9 , en prensa. 
Delmas-Marty, M. Modelos actuales de Politica Criminal. Madrid. Centro de Publicaciones - Secretaría General Técnica-Ministerio de Justicia. 1986.

Di Tulio, B. Principios de Criminología Clínica y Psiquiatría Forense. Madrid. Aguilar. 1966.

Fournier, M. V. La violencia en Costa Rica: un problema estructural. Ciencias Penales, 1999, nro. 16, pp. 61-63.

Issa, H. y Arias, M. G. Derechos Humanos en el sistema penal. San José. Universidad Estatal a Distancia. 1998.

Marchiori, H. La personalidad del delincuente. $3^{a}$ ed. México D. F. Porrúa. 1990.

Muñoz-Conde, F. La resocialización: Análisis y crítica de un mito. En: S. Mir Puig (Ed.). Politica Criminal y Reforma del Derecho Penal. Bogotá. Temis. 1982. pp.131-154.

Murillo, R. Ejecución de la pena. San José. Comisión Nacional para el Mejoramiento de la Administración de Justicia. 2002.

Reforma Penal Internacional. Manual de buena práctica penitenciaria. $2^{\text {a }}$ ed. San José. Guayacán. 2002.

Roxin, C. El desarrollo de la Política Criminal desde el Proyecto Alternativo. En: S. Mir Puig (Ed.). Política Criminal y Reforma del Derecho Penal. Bogotá. Temis. 1982. pp. 5-27.

Sáenz, M. A. La inseguridad ciudadana: los aportes de Ignacio Martín-Baró y la criminología crítica. Revista de Ciencias Sociales, Universidad de Costa Rica, 1995, nro. 69, pp. 29-41.

Sáenz, M. A. El papel de los medios de comunicación en la construcción social del fenómeno de la criminalidad. Cuadernos de Estudio del Ministerio Público de Costa Rica, 2004, nro. 8, pp. 49-57.

Salas, M. E. Mitomanías de la «política criminal» moderna. Cuadernos de Estudio del Ministerio Público de Costa Rica, nro. 8, 2004, pp. 41-48.

Salgado, Á. Modelos o paradigmas de la criminología actual. En: Asociación Colombiana de Criminología (Ed.). Lecciones de Criminología. Bogotá. Temis. 1988, pp. 15-18

Sepúlveda, J. G. Política Criminal. En: Asociación Colombiana de Criminología (Ed.). Lecciones de Criminología. Bogotá. Temis. 1988. pp. 87-107.

Universidad Estatal a Distancia. Programa de Maestría en Criminología. San José. UNED. 2001.

Universidad Estatal a Distancia (Ed.) Antología del Curso Teorías y Enfoques sobre la Sanción Penal. San José: Maestría en Criminología, UNED. 2003.

Velásquez, L. F. Política Social y Política Criminal. En: Asociación Colombiana de Criminología (Ed.). Lecciones de Criminología. Bogotá. Temis. 1998. pp. 109-120

Víquez, M. A. El Diagnóstico y la Síntesis Criminológica. Alajuela. Centro Nacional de Diagnóstico CriminológicoPenitenciario, Ministerio de Justicia. (s. f.).

Víquez, M. A. El rol del psicólogo criminológico en la institución carcelaria: una autocrítica. Revista Costarricense de Psicología, nro. 12-13, 1988, pp. 47-55.

Zúñiga, L. Política Criminal. Madrid. Colex. 2001. 
Votos de la Sala Constitucional:

Nro. 709-91 de 10 de abril de 1991.

Nro. 525-93 de 3 de febrero de 1993.

Nro. 2586-93 de 8 de junio de 1993.
Nro. 6829-93 de 24 de diciembre de 1993.

Nro. 2313-95 de 9 de mayo de 1995.

Nro. 672-97 de 31 de enero de 1997.

Nro. 3502-97 de 20 de junio de 1997. 